\title{
MicroRNA-Mediated Regulation and the Genetic Susceptibility to Anxiety Disorders
}

\author{
Yolanda Espinosa-Parrilla and Margarita Muiños-Gimeno \\ Institut de Biologia Evolutiva (UPF-CSIC)Barcelona, \\ Spain
}

\section{Introduction}

Investigation of how genetic variation within complex gene regulatory networks results in phenotypic alterations may represent a useful approach towards the understanding of human evolution and disease. In this regard, genetic studies can contribute to the identification of genes and pathways underlying the susceptibility to psychiatric disorders including anxiety disorders. However, this has shown to be difficult due to the complexity of both, the genetics and the phenotypes of these disorders. In fact, even though the estimated heritability of psychiatric disorders is high, most genetic risk alleles for these disorders have still not been identified, leading to the conclusion that either major risk alleles are scarce or that they increase risks only marginally, that is to say that their associated Odds Ratio is low. Genetic heterogeneity for complex disorders is widely accepted and, in addition, it has been suggested that non-standard factors, such as epigenetic or regulatory changes or combinations of various of these elements could be involved in the aetiology of psychiatric disorders (Burmeister et al., 2008). Accordingly, increasing evidence at a population and experimental level indicates that genetic variation at regulatory regions underlies differences in gene expression and could be a major contributor to phenotypic diversity in human populations (Buckland et al., 2005; Knight, 2005; Rockman and Wray, 2002). This may be particularly true in the case of psychiatric disorders, where changes in regulatory elements leading to small variations in the dosage of proteins involved in neuronal pathways may disrupt the fine-tuned equilibrium of complex brain functions and contribute to the development of the disease. In this respect, even though the search for susceptibility genes for anxiety disorders has led to the finding of positive associations, most of these studies have produced results that are inconsistent or not clearly replicated, indicating that the genetic basis of anxiety disorders requires further investigation using alternative approaches.

Stress has also been shown to have a critical role in the development of anxiety disorders (Lupien et al, 2009), at least partially, through mechanisms related to neural plasticity. Synaptic connections in the brain undergo experience-dependent functional or morphological changes through complex pathways that are not yet fully understood, but for which microRNAs (miRNAs) might have a critical role (Kosik et al., 2006). miRNAs are endogenous small non-coding RNAs that regulate gene expression by means of partial 
complementarity to miRNA binding sites at their target genes. These molecules have emerged as key regulators of almost every biological process including accurate control of neuronal gene expression (Krol et al., 2010). Due to their enormous regulatory potential, miRNAs could be considered as one of the most significant discoveries in molecular biology of the last decade.

This chapter aims to give insights into the role of gene regulation and, in particular, into the involvement of miRNAs in the pathophysiology of anxiety disorders, with special focus on panic disorder. We will explore the hypothesis that changes in miRNA-mediated regulation, originated from changes in the miRNAs themselves or on their target sites, may alter the dosage of proteins involved in fundamental pathways for brain function, affecting the precise homeostasis of the central nervous system and contributing to the development of anxiety disorders. The chapter will go through recent research results that, by a combination of association analyses and functional approaches, involves particular miRNAs and several candidate genes in the susceptibility for anxiety disorders and indicates that polymorphisms affecting miRNA-mediated regulation may be determinant of a range of human traits related to anxiety (Muiños-Gimeno et al., 2009; 2011).

\section{Anxiety disorders}

Even though definitions, assessments and classifications of mental disorders may vary along time, guideline criteria listed in the International Statistical Classification of Diseases and Related Health Problems, Diagnostic and Statistical Manual of Mental Disorders and other manuals are widely accepted by mental health professionals. According to the latest version from the Diagnostic and Statistical Manual of Mental Disorders, Fourth Edition, Text Revised (DSM-IV-TR) (American Psychiatric Association, 2000), anxiety disorders include a broad category of heterogeneous disorders where the primary feature is abnormal or inappropriate anxiety. The central and unifying features of all anxiety disorders are heightened sense of arousal or fear that is episodic or continuous and may be related to exposure to a specific trigger. There are both psychological and physiological components to anxiety disorders such as worry and fear or increased heart rate and sweating. Symptoms of anxiety are also part of a normal process called the 'fight or flight' phenomenon. This means that the body is preparing itself to either fight or protect itself or to flee a dangerous situation. These symptoms become problematic when they occur without any recognizable stimulus or when the stimulus does not warrant such a reaction. Population prevalence of these disorders is approximately 16\%, when considering developed and developing countries (Kessler, 2009), and the age at onset is variable, some of them starting in the early childhood (Kessler, 2007).

Biological theories on anxiety disorders suggest abnormalities of the neurobiological pathways associated with modulating normal and pathological fear and/or stress states. In fact, animal models of stress have delineated major components of the stress response (Sullivan et al., 1999). However, nowadays, imaging studies also seek to identify the unique patterns and combinations of activated or deregulated brain regions involved in certain anxiety disorders (Gorman et al., 2000). A model that focuses on the amygdala and its interconnected structures has been proposed for anxiety disorders. The amygdala and hippocampus are important nuclei of the limbic system that regulate emotions and memory 
storage, respectively. The amygdala seems to play an essential role in the acquisition of conditioned fear and the expression of innate and learned fear responses (Li et al., 1996). Specifically, the model describes 2 parallel pathways carrying information to the amygdala: the thalamic-amygdala pathway and the cortico-amygdala pathway. Sensory information (coming from either one out of these two pathways) enters the lateral amygdala, from which processed information passes to the central nucleus. The central nucleus, then, acts as the central component of the fear neural circuitry and projects to multiple brain systems involved in the physiologic and behavioural responses to fear. Projections from the amygdala to the hypothalamus take 2 primary routes: 1) the lateral hypothalamus, leading to sympathetic activation; and 2) the paraventricular nucleus, leading to activation of the hypothalamus-pituitary-adrenal axis.

Nowadays the DSM-IV-TR classifies anxiety disorders into several disorders: acute stress disorder, agoraphobia (with or without a history of panic disorder), anxiety disorder due to general medical condition, generalized anxiety disorder, obsessive-compulsive disorder, panic disorder (with or without agoraphobia), phobias (including social phobia), posttraumatic stress disorder and substance-induced anxiety disorder. However, categorical classification of these disorders has not been static during the years and remains still controversial (American Psychiatric Association, 2000). Problems arise from the overlapping of phenotypes within the broader context of anxiety disorders, variable expressivity of panic and anxiety or depression, and the presence of phenocopies within a family. On the other hand, since the diagnostic remains purely clinical, genetic studies are arduous to perform. The use of dimensional personality traits, such as shyness, behavioural inhibition and neuroticism, in order to better define an anxiety phenotype instead of clinical diagnosis has been proposed as a solution to this problem (Hettema et al., 2001; Kessler et al., 2005; Smoller and Tsuang, 1998). Within anxiety disorders, in this chapter we will mainly focus on panic disorder and obsessive-compulsive disorder

\subsection{Panic disorder}

The DSM-IV-TR defines panic disorder as the spontaneous, unexpected occurrence of panic attacks followed by persistent concern, worry, and anxiety about having additional panic attacks. Panic attacks are defined as a discrete period of intense fear or discomfort (no more than 30 minutes) that develops abruptly and reaches a peak within 10 minutes, in which at least 4 of 13 symptom criteria are met. Some of these criteria include cardiac palpitations, sweating, feelings of choking, fear of losing control, and fear of dying. Panic attacks often mimic symptoms of physical complaints such as a heart attack or other life-threatening illnesses (American Psychiatric Association, 2000) and typically occur spontaneously, with no apparent trigger. However, there is evidence that shows that for the majority of patients mild phobic or hypocondriacally symptoms precede the panic attacks. It has been therefore proposed that panic attacks are more unpredictable than unexpected (Gratacos et al., 2007). Panic disorder may manifest with or without accompanying agoraphobia. However, agoraphobia can also occur without panic disorder, and panic attacks can occur in the absence of panic disorder. Comorbidity with depressive and addictive disorders is frequent as much as a lifetime prevalence rate of $50-60 \%$. Life prevalence of panic disorder is $1-2 \%$ (Regier et al., 1990) and twice as many women suffer from the disorder if compared to men (Weiller et al., 1998; Weissman et al., 1997). Panic disorder has a bimodal age at onset 
distribution, with highest incidence in late adolescence and a second peak in the mid 30s (Sansone et al., 1998). This disorder is, however, less often observed in the elderly (Gratacos et al., 2007). Panic disorder has moderate estimated heritability rate of $44 \%$ (van den Heuvel et al., 2000), and results from a meta-analysis performed on genetic epidemiology studies showed that there is a significant association between panic disorder in the probands and panic disorder in the first-degree relatives $(\mathrm{p}<0.0001)$ (Hettema et al., 2001). Furthermore, risk for panic disorder increases in adult first-degree relatives, when the age at onset of the proband is under twenty years of age (17-fold to 6-fold), suggesting that age at onset might be useful in differentiating familial subtypes of panic disorder (Goldstein et al., 1997). In addition, panic disorder and agoraphobia with panic attacks were shown to be more than five times more frequent in monozygotic twins than in dizygotic twins (Torgersen, 1983). This was further corroborated by a later study which found a significantly higher concordance among monozygotic than dizygotic twins for panic disorder (73\% vs. 0\%), confirming a role for genetic factors in panic disorder, but not for spontaneous panic attacks (57\% vs. $43 \%$ ) (Perna et al., 1997). Agoraphobia is also thought to be a more severe variant of panic disorder as suggested by the fact that the risk of panic disorder is increased among the relatives of patients with agoraphobia $(8.3 \%)$ and the relatives of patients with panic disorder (17.3\%). However, while the risk for agoraphobia is also increased among the relatives of patients with agoraphobia $(11.6 \%)$, it is not among the relatives of patients with panic disorder (1.9\%) (Noyes et al., 1986).

\subsection{Obsessive-compulsive disorder}

Obsessive-compulsive disorder is characterised by obsessions and compulsions. Obsessions are recurrent intrusive and unwanted thoughts that the sufferer cannot dispel. Common themes of the obsessive thoughts include thoughts that the person may cause harm to others or that harm may befall others, or thoughts that the person or others are contaminated. Other common themes are centred on the need for order, symmetry or perfection. The obsessive thoughts are associated with negative feelings, usually anxiety, but other emotions such as disgust, guilt or shame may also be experienced. As a response to these feelings generated by the obsessive thoughts, the person may perform compulsions, and performance of the compulsions temporarily decreases the negative effect. The compulsions are stereotypic, ritualised behaviours that are usually observable but which may include covert mental rituals. Common rituals include repetitive checking, washing or cleaning, or repetitive rearranging and ordering of objects. Examples of covert mental rituals include repetitive counting, praying or thinking magical statements (Gelder et al., 2001). In summary, the obsessions and compulsions are distressing, time-consuming, and often lead to impairment in occupational, scholastic, or social functioning. According to the DSM-IVTR to meet criteria for obsessive-compulsive disorder, the individual must report ineffective efforts to resist, neutralise, or suppress thoughts or behaviours with other thoughts or actions. In addition, the thoughts must be distinct from those associated with other anxiety disorders, and the individual must acknowledge that the thoughts are a product of his or her own mind (American Psychiatric Association, 2000). The disorder affects approximately $1-3 \%$ of adults (Kessler et al., 2005) and is ranked by the World Health Organization as among the ten most disabling medical conditions (Grisham et al., 2008). Although there is strong evidence that obsessive-compulsive disorder has a genetic component (Hettema et 
al., 2001), definitive single domain or integrative models have not yet been established (Stein, 2002). The broader obsessive-compulsive disorder phenotype has been divided into subgroups that are potentially more etiologically and genetically homogenous: symmetry/order, aggressive/checking, contamination/cleaning and hoarding (Mataix-Cols et al., 2005). A more controversial fifth dimension may be also included, consisting of somatic, sexual, religious obsessions and mental rituals ("pure obsessional") (Mataix-Cols et al., 2006). Obsessive-compulsive disorder usually begins before 25 years of age and often in childhood or adolescence.

\section{Problems of the genetic study of anxiety disorders - high level of regulatory control in brain}

The hereditary basis for psychiatric disorders was already recognised at the turn of the nineteenth century. After that, genetic influence on all major psychiatric disorders has been consistently demonstrated by twin and adoption studies (Plomin et al., 1994). In fact, estimated heritabilities for bipolar disorder, schizophrenia and autism $-80 \%$ to more than $90 \%$ (Bespalova and Buxbaum, 2003; Gupta and State, 2007; Kieseppa et al., 2004; McGuffin et al., 2003; Sullivan et al., 2003) have been shown to be much higher than that of breast cancer $-5 \%$ to $60 \%$ - for instance (Locatelli et al., 2004; Schildkraut et al., 1989), for which several genetic factors are now well established (Plomin, et al., 1994). However, although genetic influences on psychiatric disorders have been well established, localization of genes responsible for these effects has proven to be extremely difficult. This is probably due to several reasons, among others: Problems arising from the difficult diagnosis of Psychiatric disorders, the probable multifactorial and polygenic origin of these disorders and the high level of regulatory control and gene interactions to what human brain and behaviour are exposed.

Regarding the latter, the search for susceptibility genes for anxiety disorders has classically focused on neurotransmitters and members of neurotransmitter synthesis and degradation pathways, although other groups of molecules including genes involved in neurodevelopment and synaptic plasticity have been also studied more recently. Nevertheless, the complexity of the central nervous system requires not only of a precise function of its formal components but also of an accurate gene regulation of the system. Hence, genetic variation in regulatory regions is nowadays recognized as a major contributor to phenotypic diversity (Buckland et al., 2005; Knight, 2005; Rockman and Wray, 2002). Taking into account the importance that minimal changes in gene regulation could have in gene dosage, and gene dosage in turn, to genetic susceptibility to disease, regulator elements acting in the brain should be included in every psychiatric candidate gene study. Accordingly, post-transcriptional regulation, previously underestimated, is growing in importance and is thought to play an important role on mammalian development and disease (Sun and Tsao, 2008). Contrary to what was thought during many years, it is nowadays accepted that more than half of the human genome is transcribed and that most of the generated transcripts $(\sim 98 \%)$ are actually non-protein coding (Mattick, 2009). RNAs that do not code for proteins and directly function as RNAs are called non-protein coding RNAs (ncRNAs). Importance of ncRNAs is supported by the fact that their accumulation tends to increase with organism complexity along the evolutionary scale (Mattick, 2009) and, even though a recognized function is lacking for most of these ncRNAs, they are mostly predicted to have regulatory functions (Costa, 2010) and should thus be considered as candidate genes for disease. 


\section{MicroRNAs}

In the last few years additional species of ncRNAs have increasingly been discovered (Costa, 2010), among which, small ncRNAs, and among them microRNAs (miRNAs), attract particular attention because of their role in processes such as RNA silencing and modification (Kawaji and Hayashizaki, 2008). miRNAs are endogenous small ncRNAs that regulate gene expression by means of partial complementarity to miRNA binding sites at their target genes (Bartel, 2004). Recent estimates indicate that they regulate more than 30\% of all protein-coding genes, building complex regulatory networks that control almost every cellular process (Filipowicz et al., 2008). The founding member of the miRNA family, lin-4, was identified in C. elegans in 1993 through a genetic screening for defects in the temporal control of post-embryonic development (Lee et al., 1993). Withal, it was not until 2001 that miRNAs were recognized as a large and phylogenetically extensive family of non-protein coding RNAs representing a new layer of gene regulation (Lagos-Quintana et al., 2001; Lau et al., 2001; Lee and Ambros, 2001). Since then, the number of identified miRNAs has increased vertiginously, in humans for example, their growth has ranged from none, in 2001, to a total of 1424 human miRNAs that are being recognized by the last version of the miRNA database (April 2011, Sanger miRBase, release 17.0). Remarkably, during the last 4 years (2007-2011), the number of identified miRNAs has been triplicated. Consequently, publications and knowledge on this class of small RNAs has also increased considerably. As a matter of fact, the number of pubmed publications on miRNAs was of five in 2001, while nowadays there are roughly 12000 . It is estimated that miRNAs will comprise $1 \%-5 \%$ of animal genes (Bartel, 2004), being, in consequence, one of the most abundant classes of regulators in the genome.

On the other hand, it is known that a single miRNA can target as many as several hundred genes, and that one gene can be targeted synergistically by more than one miRNA. Taken together, miRNAs form an interconnected regulatory network that does not simply turn genes on or off, but are thought to "tune" the expression level of their target genes (Sun and Tsao, 2008). Post-transcriptional regulation by miRNAs may thus represent an important mechanism through which the central nervous system accomplishes its demands for precise but rapid changes in gene regulation. In fact, both the synthesis and degradation of RNAs are likely to require less time and energy than those of proteins. Consequently, non-protein coding RNAs and particularly, miRNAs, are suitable candidates for the regulation of a constantly changing microenvironment, like the central nervous system.

The importance of miRNAs is made evident by their conservation along evolution and by the multiple processes in which they are implicated, such as developmental timing, cell differentiation and morphogenesis (Stark et al., 2005), synaptic plasticity (Schratt et al., 2006), regulation of immunological functions (Pauley and Chan, 2008) and stress response (He et al., 2007). Different types of cellular stress have been shown to alter miRNA levels; for example, hypoxia-responsive transcription factors such as nuclear factor-kappa B and p53 induce miRNA genes (He et al., 2007; Taganov et al., 2006). In general, studies on oxidative stress, cold stress and nutrient deprivation indicate that long-term stress may have an impact on miRNAs and on global gene expression, perhaps leaving tissues more susceptible to pathogenic processes. It is thought that chronic stress can initiate cellular reprogramming through alterations in miRNA expression or activity, leading to sustained changes in gene expression and cellular physiology (Hudder and Novak, 2008). It is also worth mentioning that miRNAs are also involved in cell cycle progression and apoptosis (Carleton et al., 2007), as emphasized 
by their implication in cancer or in endocrine regulation of energy homeostasis, (Poy et al., 2004).

In particular, miRNAs have important functions in the brain and have been involved, among others, in learning and memory (Fiore and Schratt, 2007) as well as in synaptic plasticity. The prime example of a miRNA implicated in synaptic plasticity in mammalian neurons is miR-134, which localizes to dendrites close to synapsin-positive puncta (Schratt et al., 2006). Its over-expression causes a significant decrease in dendritic spine size, while its depletion leads to a small increase in spine volume. miR-134 targets LIMK1 (Lim-domaincontaining protein kinase 1), whose activity is controlled by BDNF and which is involved in actin filament dynamics, a key step in the cytoskeletal modifications of spines associated with plasticity. The concomitant over-expression of miR-134 with a mutated form of LIMK1, that has a defective target site, rescues the alterations in spine morphology, indicating that the spine size defects caused by miR-134 are indeed due to the deregulation of LIMK1 (Schratt et al., 2006). Furthermore, miR-134-mediated repression of LIMK1 is relieved upon BDNF stimulation of synaptic plasticity, showing that neuronal activation intervenes to put a brake on miRNA-mediated silencing. Finally, another indication of the involvement of microRNAs in controlling local protein translation and synaptic function comes from a recent study that demonstrated that miR-128 is deregulated in HIV-1 encephalopathy (a manifestation of HIV-1 infection that often results in neuronal damage and dysfunction) and that, in addition, miR-128 inhibits the expression of SNAP25, a pre-synaptic protein that regulates $\mathrm{Ca}^{++}$responsiveness (Eletto et al., 2008). The degree of complexity of miRNA pathway regulation has been revealed to be particularly high when studying neurons where several mechanisms of control have been discovered, such as the transport of miRNAs to distal sites in dendrites, the association of miRNA regulation with synaptic activation, or the reported role for the rapid miRNA turnover in neurons regarding miRNA activityregulation (Reviewed in Krol et al., 2010).

Another interesting observation that illustrates how much more complicated miRNAmediated regulation of mRNAs can be is based on initial studies that show that miRNAs are prone to tissue-specific RNA editing. Editing is a post-transcriptional mechanism, by which some RNA molecules are altered to contain bases not encoded in the genome (specific nucleotides are either deleted, inserted or modified to change one nucleotide into another). Such editing events alter the properties of miRNAs and seem to regulate alternative mRNA: miRNA interactions. This has been, at least, demonstrated by miR-376 targeting of a different set of genes after RNA editing in different tissues (Erson and Petty, 2008; Kawahara et al., 2007).

\section{MicroRNAs and anxiety disorder}

In addition to the modulation of physiological functions and due to their important regulatory role in processes of physiopathological relevance, a close relationship between miRNAs and human disease has been described. Regulatory changes that alter miRNA activity can be caused by both in cis and trans factors (relative to the locus coding for the miRNA), making possible to schematically group known miRNA-related diseases based on the specific process altered. Cis deregulation of miRNAs can be caused by chromosomal alterations, epigenetic modifications, polymorphic promoter elements and polymorphisms within the miRNA itself (pri-, pre- and mature miRNA sequences). Trans factors affecting 
miRNA activity, on the other hand, include functional mutations in the proteins involved in miRNA transcription, processing and targeting, and polymorphisms in miRNA target sites (poly-miRTS). We, ourselves, based our research on anxiety disorder on the hypothesis that changes in miRNA-mediated regulation, originated from changes in the miRNAs themselves ( $c i s)$ or on their target sites (trans), could alter the dosage of proteins involved in fundamental pathways of brain function, affecting the fine-tuned central nervous system homeostasis and contributing to the development of anxiety disorders. In an attempt of identifying genetic factors related to anxiety, we divided our strategy into the study of genetic variation in regulatory regions of candidate genes for anxiety disorders and the genetic study of miRNA genes "per se". As described later, even though major risk alleles have not been found, results on these studies indicate that genetic variation affecting miRNA-mediated regulation may be underlying a range of anxiety related phenotypes, being the first time that miRNAs are involved in the pathophysiology of human anxiety disorders (Muiños-Gimeno et al., 2009; 2011). Table 1 shows a list of all miRNAs that have been involved in anxiety disorders.

\subsection{Cis-deregulation involving miRNAs and disease}

Cis-deregulation of miRNAs has been involved in several human disorders. Early clues linking chromosomal alterations in miRNA loci and disease came from observations in chronic lymphocytic leukaemia (CLL), where chromosome band 13q14, commonly lost or altered in CLL patients, was found to harbour miR-15 and miR-16 (Calin et al., 2002). Both miR-15 and miR-16 were later shown to target the 3'UTR of BCL2, a well- known anti-apoptotic oncogene (Cimmino et al., 2005). Initial observations that miRNA genes were located on genomic instability and fragile sites by Calin et al. (Calin et al., 2004) led to further analyses that have demonstrated deregulated miRNA expression profiles in various diseases.

With respect to disorders of the central nervous system an increase in miR-9, miR-125b and miR-128 levels was detected in the hippocampus of Alzheimer's disease brains (Lukiw, 2007). Later, miRNA expression profiles of human brain tissue from individuals with Alzheimer's disease at different stages of the disease were compared (Wang et al., 2008a). This comparison reported significantly decreased miR-107 levels in patients with even the earliest stages of Alzheimer's disease. When further analyzing the role of this miRNA, the authors concluded that miR-107 might be involved in accelerated disease progression through regulation of the beta-site amyloid precursor protein-cleaving enzyme 1 (BACE1). Moreover, other studies demonstrated that miR-29a, miR-29b-1, and miR-9 can also regulate $B A C E 1$ expression in vitro and that these miRNAs were also decreased in patients with Alzheimer's disease, resulting in high BACE1 protein levels in patients (Hebert et al., 2008). On the other hand, reduced expression of miR-133b has been observed in dopaminergic neurons of Parkinson's disease patients and reduced levels of this miRNA have been thus associated with the typical degeneration of this type of neurons in Parkinson disease (Kim et al., 2007). Interestingly, distinct miRNA expression patterns have also been implicated in chronic psychiatric disorders: miR-26b, miR-30b, miR-29b, miR-195, miR-92, miR-24, miR$30 \mathrm{e}$, for instance, were shown by microarray and quantitative reverse transcriptasepolymerase chain reaction to be decreased in samples from individuals with schizophrenia (Perkins et al., 2007). However, the way in which these miRNAs and their targets may be involved in common complex neurological and psychiatric disease states are yet to be examined. Concerning mutations in miRNAs or in their promotor sequences and in relation 
to schizophrenia, two known SNPs, located in the adjacent +/- 100 bp genomic region of miR-206 and miR-198 were claimed to be associated with schizophrenia. One of them, in the miR-206 adjacent genomic region, remained significant after correction for multiple testing. In order to elucidate what biological signalling network might be the one affected by these miRNAs in schizophrenia, the authors performed target predictions for both miRNAs. Target predictions rendered a list of 15 genes that were predicted to be corregulated by both miRNAs. Interestingly, two of the common targets had been previously related to schizophrenia; CCND2 had been shown to be deregulated in post-mortem schizophrenia brains and PTPN1 had been positioned under a significant linkage peak (Hansen et al., 2007). Similar studies have implicated mutations in miRNAs or their regulatory regions with different diseases. Worth mentioning is a common SNP within pre-miR-146a that was reported to be strongly associated with papillary thyroid carcinoma. (Jazdzewski et al., 2008; 2009). This study is one of the few studies that clearly evidences that polymorphisms in miRNA coding regions can lead to disease and contrary to what is generally thought, the study proposes that mature miRNAs from the passenger strand may, as well, regulate many genetic processes. This is particularly interesting since the study uncovers the fact that miRNA processing and action are still to be deeply studied and that, as in every emerging topic of research, there might be false dogmas that should be redirected.

\subsubsection{Association studies of miRNA genes with anxiety disorder}

As stated in the previous section, allelic changes as well as genomic variants involving either miRNAs or their regulatory machinery may represent an important source of phenotypic variation and contribute to the susceptibility for complex disorders. Even though poorly considered until now, association studies using SNPs in miRNA genomic regions might help to evaluate the involvement of miRNAs genes in disease. In this regard, a panel of SNPs covering miRNA regions suitable for association studies was designed, constructed and used for the study of panic disorder (Muiños-Gimeno et al, 2010; 2011). Prior to the design of the SNP panel, the first step consisted in the analysis of the genomic distribution and genetic variation of all at that moment known miRNAs-containing regions. The analysis of the SNP coverage on miRNAs revealed that miRNA regions are characterized by a lower density of SNPs than the rest of the genome. In fact, at the moment of the panel design, only 24 SNPs (dbSNP 125) mapped within the miRNA sequences of 325 miRNAs, (Sanger miRBase release 7.1) -and interestingly none of them was located within a mature miRNA sequence-; this represented a density of 0.86 SNPs per kb at miRNA regions compared with the observed average of 3.99 SNPs/kb SNP for the whole human genome. The lack of mutations identified at the mature miRNAs was in agreement with the reported negative selection acting at both miRNAs as well as miRNA target sites. Existence of negative selection in conserved miRNA target sites at 3'UTRs has already been described (Chen and Rajewsky, 2006). Likewise, it has been extensively proposed that SNP density is lower in miRNA loci with respect to their flanking regions (Saunders et al., 2007). However, screening of SNPs from public databases deals with the problem of SNP ascertainment bias, mainly due to underrepresentation of low-frequency variants and the fact that not all the genome has been equally characterized. Remarkably, very recently Quach et al. (2009) confirmed this lower SNP density by re-sequencing 117 miRNAs in four different human reference populations, therefore avoiding ascertainment bias coming from public databases. Their analyses reported a lower SNP density in miRNAs than in other non-coding regions, 
which were shown to be twice as dense. The study also showed that strong purifying selection affects the sequence corresponding to the mature miRNA (particularly the first 14 nucleotides, where no mutation is tolerated) as well as the complementary miRNA sequence $\left(\right.$ miRNA $\left.^{*}\right)$, stem region and loop (Quach et al., 2009). In summary, these studies indicate that mutations in miRNA hairpins or in miRNA binding sites, such as the previously mentioned SNP occurring in miR-146a, are likely to be deleterious and may have severe phenotypic consequences on human health. Therefore, extensive re-sequencing in patients and controls of 3'UTRs and of miRNAs themselves, would be definitely interesting to test the putative role of miRNA-mediated regulation in the susceptibility for anxiety disorders. Unfortunately, only 117 out of the actual 1424 miRNAs could be resequenced in this study of Quach. In this regard, the fast increase in the number of newly discovered miRNAs is being one of the main handicaps that researchers are facing. This is further complicated by the frequent corrections and modifications miRNAs suffer in their annotation (as far as sequences, nomenclature, etc).

The exponential increase in the number of miRNAs discovered was also a handicap for the design of the SNP panel used later for association analyses in disease, since the number of known miRNAs increased more than $50 \%$ from the beginning of the design to the moment that the association analyses were performed. Apart from the analyses in disease, the SNPs panel was also employed to study variability in miRNAs regions among different populations. After genotyping a group of 341 Spanish control individuals, allele frequencies between the HapMap European population and the specific North-East Spanish (Catalan) population were compared and pointed out to two genomic regions showing geographic genetic variation among populations. Remarkably, one of these regions is the LCT region (containing hsa-miR-128-1), a region that has already been shown to be under selective pressure (Beja-Pereira et al., 2003; Hollox, 2005).

Our group has been the first to show an implication of miRNAs in the aetiology of panic disorder (Table 1). Case-control studies for the 712 SNPs in the panel tagging human miRNA regions were performed in 203 Spanish patients with panic disorder and in 341 controls. Two SNPs associated with panic disorder: rs6502892 tagging miR-22 $(\mathrm{p}<0.0002)$ and rs11763020 tagging miR-339 ( $\mathrm{p}<0.00008$ ). Other SNPs tagging miR-138-2, miR-488, miR491 and miR-148a regions associated with different panic disorder phenotypes, panic disorder with or without agoraphobia, or age at onset. Replication in a north-European sample of 321 anxiety patients and 653 controls from Finland and 102 patients and 829 controls from Estonia confirmed the association for several of these miRNAs. Associations alone did not result conclusive, as the associated SNPs did not resist correction for multiple testing (Muiños-Gimeno et al., 2011). Modest associations, however, are repeatedly identified in most studies on panic disorder, a disorder for which multiple genes of small effect interacting with each other and/or with non-genetic factors have been proposed to participate in disease susceptibility (Smoller and Tsuang, 1998). In fact, results on whole genome association studies suggest that susceptibility alleles are likely to be modest in effect size and require large sample sizes for detection (Sklar et al, 2008). Performing functional studies rather than replicating associations in other cohorts is gaining more attention nowadays, as recent association studies in complex disorders do not have enough power and have failed to replicate. In order to search for possible causal variants that might be in linkage disequilibrium with the associations, we re-sequenced the pre-miRNA sequences of these six associated miRNAs as well as their flanking regions. This analysis identified ten common and fourteen rare allelic variants, in addition to four short deletions, none of which 
was located within the mature or pre-miRNA sequences, and therefore no effect in the targeting spectrum of the studied miRNA was predicted to occur. In contrast, effects derived from variants in the proximity of pre-miRNA sequences, if any, would be related to changes in miRNA dosage (Muiños-Gimeno et al., 2011). Indeed, variants affecting miRNA expression and processing could explain the neuronal disequilibrium proposed for psychiatric disorders, where correct dosage could be crucial.

Taking into account the fact that the targeting spectrum of the associated miRNAs was unlikely to be affected, we aimed to identify candidate genes for panic disorder, among those predicted to be targeted by the associated miRNAs, and to functionally validate these predictions. miRNA over-expression experiments using a luciferase-based assay indicated a repression of RGS2, BDNF, HTR2C, and MAOA by miR-22, of POMC by miR-488, of GABRA6 by miR-138-2 and of CCKBR by miR-148a (Muiños-Gimeno et al., 2011). All of these genes have been implicated in the aetiology of anxiety disorders, often in a dosage dependent manner (Maron et al, 2010). For instance, serotonergic pathways have been involved in the pathogenesis of anxiety disorders, mainly because of the observation that patients with anxiety disorders respond well to serotonergic medications and because the occurrence of panic attacks has been reported after administration of serotonergic agonists (Sklar et al., 2008; Wu et al., 2008). Interestingly, the expression of RGS2 has been demonstrated to be a quantitative trait (Betel et al., 2008), for which association with a haplotype within the 3'UTR has been reported (Maron et al., 2010; Koene et al., 2009). Moreover, RGS2 knock-out mice show increased anxiety-like behaviour compared to their wild-type counterparts (Yalcin et al., 2004), remarkably, the expression of RGS2 was significantly reduced in experiments where over-expression of miR-22 was simulated in neuroblastoma SH-SY5Y cells (Muiños-Gimeno et al., 2011). Interestingly, another downregulated gene after miR-22 over-expression was ASCL1, which has been demonstrated to be essential for the development of central serotonergic neurons and has been proposed as a candidate for Ondine syndrome, a rare disorder of the chemical control of breathing (Pattyn et al, 2004, de Pontual et al., 2004). Other down-regulated genes also have important neuronal functions, such as CHGA with roles in neuroendocrine secretion (Taupenot et al., 2003) or the promotion of dendritic outgrouth by NPTX2 (Tsui et al., 1996). Furthermore, it is worth remarking the deregulation of the corticotropin releasing hormone $(\mathrm{CRH})$ signalling pathway associated with the over-expression of miR-488 in the same cellular system, this is a crucial pathway activated in response to stress and includes the pro-opiomelanocortin (POMC) gene. POMC is the precursor molecule for several important components of the hypothalamicpituitary-adrenal axis (Figure 1), which is involved in the neurobiology of mood and anxiety disorders (Swaab et al., 2005). Regardless of the genetic mechanism involved in these associations, the development of the phenotype could depend upon the expression and activity of these miRNAs, some of which are known to be expressed or to have important functions in the brain. miR-22, for example, is expressed ubiquitously in several tissues including the pituitary and the midbrain; miR-488 is a brain-enriched miRNA that is more abundantly expressed in the hippocampus and cerebellum; miR-138 is highly enriched in the brain, including the frontal cortex, the hippocampus and the midbrain (Betel et al., 2008). Furthermore, miR-138 is localized within dendrites, and is known to negatively regulate the size of dendritic spines in rat hippocampal neurons (Siegel et al., 2009)

Finally, it is important to mention two studies that, using animal models, involve particular miRNAs with anxiety behaviour. The diversity of phenotypes available for several mouse strains has allowed to determine differences in miRNA expression across inbred strains and 
to analyze their correlation with both phenotype data and mRNA regulation (Parsons et al., 2008). Following this approach the authors managed to nominate miRNAs that have potential roles in anxiety, exploration, and learning and memory. In particular, they found correlation between the differential expression of miR-34c and mir-323 with behavioural measures for anxiety. It is interesting to highlight that the authors also suggest a miR-34cmediated regulation of genes involved in long-term depression and neuroactive ligand receptors. This study has opened the door for further research using mouse genetic reference populations and importantly points out to two miRNAs, miR-34c and miR-323, as candidate genes for anxiety disorders (Parsons et al., 2008). Another recent study working with Fischer 344 rats, as an animal model for the study of vulnerability to repeated stress and therefore for anxiety and mood disorders-, described a role for miR-18a in the regulation of hypothalamic-pituitary-adrenal axis. Suppressed or decreased hypothalamicpituitary-adrenal axis responses have been repeatedly described on chronically stressed animals upon re-exposure to the same stressor. This phenomenon, called habituation, is likely to protect the organism from hypercoticosteroidism and is thought to be partly controlled via activation of glucocorticoid type I (mineralocorticoid) and/or glucocorticoid type II (glucocorticoid receptor). Interestingly, Fischer 344 rats have been reported to exhibit no habituation of hypothalamic-pituitary-adrenal axis activity during restraint stress episodes. The study of Shusaku et al. reported an increased expression of miR-18a and lower glucocorticoid receptor protein levels in the hypothalamic paraventricular nucleous of Fischer 344 rats. This along with the fact that miR-18a seems to inhibit glucocorticoid receptor translation (Figure 1) suggests that miR-18-a could be a vulnerability factor for the development of stress-related behaviours (Shusaku et al., 2008). Consequently, miR-18a together with miR-34 and miR-323 should be considered as potential susceptibility factors for stress-related disorders such as panic and mood disorders (Table 1).

\subsection{Trans-deregulation of miRNAs}

Trans-deregulation of miRNAs can be broadly summarized into structural alterations involving genes that are important in miRNA biogenesis (e.g Fragile $X$ and DiGeorge syndromes), or mutations in miRNAs target mRNA sequences (e.g. Tourette syndrome and pathological aggressiveness). A few examples of human diseases affecting the central nervous system caused by deregulation in the miRNA pathway have been reported, such as cancer or Fragile X Syndrome (Gong et al., 2005). Fragile X syndrome (FX) is one of the most common forms of mental retardation, and is characterized by abnormalities in the structural development of dendritic spines. It is caused by a CGG repeat in the 5'UTR of the FMR1 gene, which is located on the long arm of chromosome $X$. The condition becomes clinically manifest when the repeat expands as the gene is passed from generation to generation, until its transcription is completely shut down in the full-blown syndrome (Penagarikano et al., 2007). The current view is that Fragile $X$ protein (FMRP) associates with endogenous miRNAs and with Ago1 -in mammals -to translationally repress a subset of dendritic mRNAs (Jin et al., 2004) and that the disease is caused by the deregulated expression of its mRNA targets which encode factors required for synaptic plasticity and development. In relation to this, another study carried out in Drosophila has shown an interesting overlapping between the composition of FMRP-containing neuronal granules and P-bodies, which suggests that these classes of granules might be similar not only in composition but also in function (Hillebrand et al., 2007). Similarly, most cases of DiGeorge syndrome 


\begin{tabular}{|c|c|c|}
\hline miRNA & Involvement with Anxiety Disorder & Reference \\
\hline $\operatorname{miR}-18 a$ & $\begin{array}{l}\text { Possible repressor of the glucorcorticoid receptor gene } \\
\text { in the hypothalamic paraventricular nucleus regulating } \\
\text { stress responses }\end{array}$ & $\begin{array}{l}\text { Shusaku et al., } \\
2008\end{array}$ \\
\hline $\operatorname{miR}-34 \mathrm{c}$ & $\begin{array}{l}\text { Correlation between differential expression of this } \\
\text { miRNA and behavioural measures for anxiety in mice }\end{array}$ & $\begin{array}{l}\text { Parsons et al., } \\
2008\end{array}$ \\
\hline $\operatorname{miR}-323$ & $\begin{array}{l}\text { Correlation between differential expression of this } \\
\text { miRNA and behavioural measures for anxiety in mice }\end{array}$ & $\begin{array}{l}\text { Parsons et al., } \\
2008\end{array}$ \\
\hline $\operatorname{miR}-128$ & $\begin{array}{l}\text { Association of an allelic variant in the target site for } \\
\text { miR-128 in NTRK3 (ss102661458) with Panic Disorder - } \\
\text { Reduction of NTRK3 repression }\end{array}$ & $\begin{array}{l}\text { Muiños-Gimeno } \\
\text { et al., } 2009\end{array}$ \\
\hline miR-509 & $\begin{array}{l}\text { Association of an allelic variant in the target site for } \\
\text { miR-509 in NTRK3 (ss102661458) with Panic Disorder - } \\
\text { Reduction of NTRK3 repression }\end{array}$ & $\begin{array}{l}\text { Muiños-Gimeno } \\
\text { et al., } 2009\end{array}$ \\
\hline miR-765 & $\begin{array}{l}\text { Association of an allelic variant in the target site for } \\
\text { miR-765 in NTRK3 (ss102661460) with Panic Disorder - } \\
\text { Reduction of NTRK3 repression }\end{array}$ & $\begin{array}{l}\text { Muiños-Gimeno } \\
\text { et al., } 2009\end{array}$ \\
\hline $\operatorname{miR}-485-3 p$ & $\begin{array}{l}\text { Association of an allelic variant in the target site for } \\
\text { miR-765 in NTRK3 (rs28521337) with Obsessive- } \\
\text { Compulsive Disorder }\end{array}$ & $\begin{array}{l}\text { Muiños-Gimeno } \\
\text { et al., } 2009\end{array}$ \\
\hline $\operatorname{miR}-22$ & $\begin{array}{l}\text { Associated with Panic Disorder - Repression of RGS2, } \\
B D N F, H T R 2 C \text {, and MAOA }\end{array}$ & $\begin{array}{l}\text { Muiños-Gimeno } \\
\text { et al., } 2011\end{array}$ \\
\hline miR-138-2 & $\begin{array}{l}\text { Associated with age at onset in Panic Disorder - } \\
\text { Repression of GABRA6 }\end{array}$ & $\begin{array}{l}\text { Muiños-Gimeno } \\
\text { et al., } 2011\end{array}$ \\
\hline miR-148a & Associated with Panic Disorder - Repression of CCKBR & $\begin{array}{l}\text { Muiños-Gimeno } \\
\text { et al., } 2011\end{array}$ \\
\hline $\operatorname{miR}-339$ & Associated with Panic Disorder & $\begin{array}{l}\text { Muiños-Gimeno } \\
\text { et al., } 2011\end{array}$ \\
\hline $\operatorname{miR}-488$ & Associated with Panic Disorder - Repression of POMC & $\begin{array}{l}\text { Muiños-Gimeno } \\
\text { et al., } 2011\end{array}$ \\
\hline $\operatorname{miR}-491$ & Associated with Panic Disorder & $\begin{array}{l}\text { Muiños-Gimeno } \\
\text { et al., } 2011\end{array}$ \\
\hline
\end{tabular}

NTRK3, neurotrophic tyrosine kinase, receptor, type 3; RGS2, regulator of G protein signaling 2; BDNF, brain-derived neurotrophic factor; HTR2C, 5-hydroxytryptamine (serotonin) receptor 2C; $M A O A$, monoamine oxidase A; GABRA6, gamma-aminobutyric acid A receptor, alpha 6; CCKBR, cholecystokinin $\mathrm{B}$ receptor; $P O M C$, proopiomelanocortin preproprotein.

Table 1. Overview of miRNAs reported to be involved in anxiety disorders. 


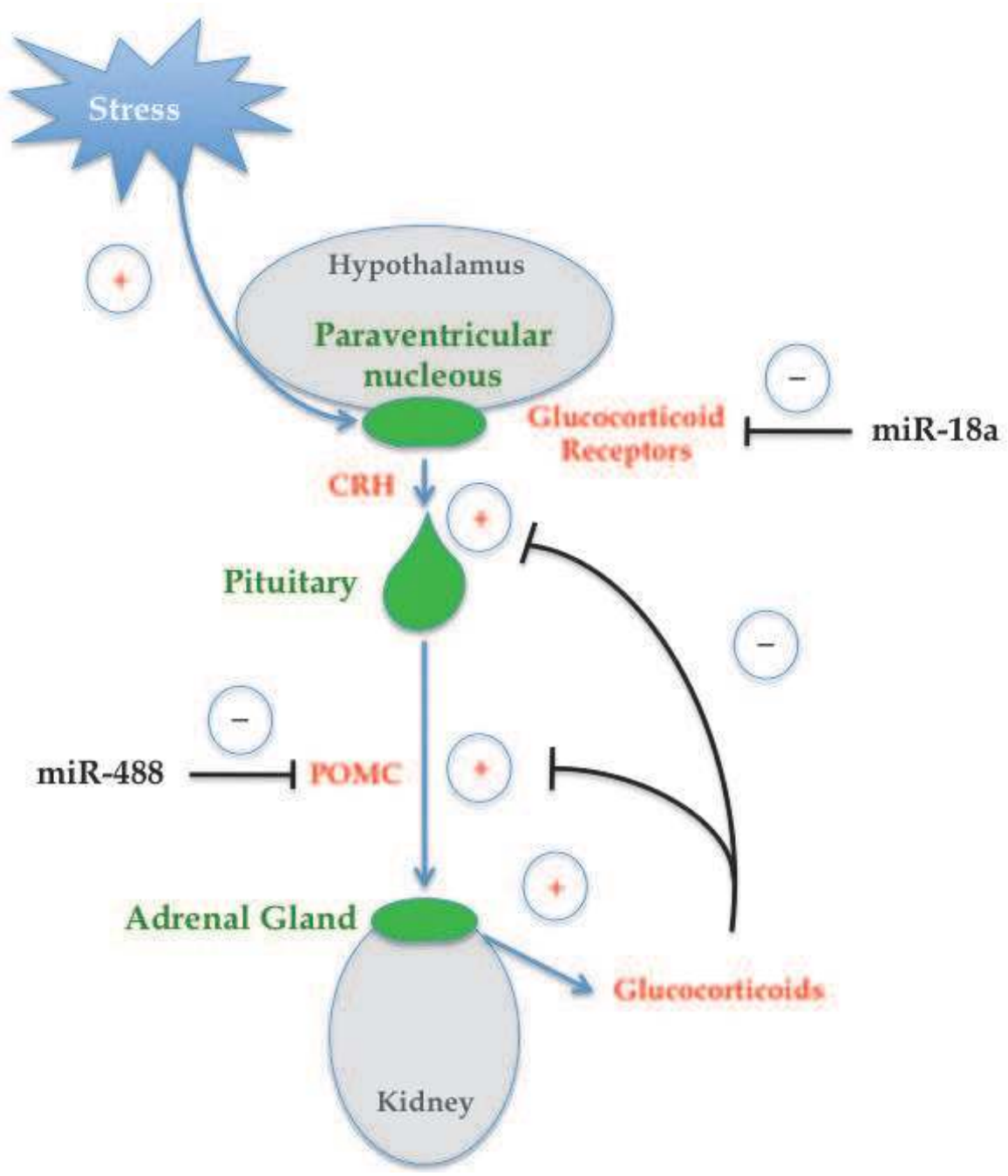

Fig. 1. Overview of the hypothalamic-pituitary-adrenal axis activation in response to stress showing the putative regulation of the pathway at two different points by miR-18a and miR488. CRH, corticotropin releasing hormone ; POMC, pro-opiomelanocortin.

result from a deletion of chromosome 22q11.2 (the DiGeorge syndrome chromosome region, or DGCR); this deletion includes the DGCR8 gene. DiGeorge syndrome is a developmental disorder characterized by mental retardation, as well as structural and functional palate anomalies, conotruncal cardiac malformations, immunodeficiency, hypocalcemia, and typical facial anomalies. DGCR8 is required for the maturation of miRNA primary transcripts. In fact, its knockdown leads to accumulation of pri-miRNAs and reduction of pre-miRNAs and mature miRNAs (Landthaler et al., 2004), indicating again a plausible involvement of miRNAs in the aetiology of the disease. 
Since 2005 until now, the number of described mutations in miRNAs target mRNA sequences (poly-miRTS) has been growing exponentially, being the majority of these studies published in the last three years. On this section we will only focus on those poly-miRTS affecting central nervous system; nevertheless, poly-miRTS have also been implicated in different disorders such as breast cancer (Adams et al., 2007), hypertension (Martin et al., 2007; Sethupathy et al., 2007), methotrexate resistance (Mishra et al., 2007), Childhood asthma (Tan et al., 2007) and colorectal cancer (Landi et al., 2008) among others. Abelson et al. were the first to associate a sequence variant in a miRNA target site with disease in 2005 (Abelson et al., 2005). They reported a rare sequence variant enhancing a target site for miR189 in the SLITRK1 (Slit and TRK-like family member 1) gene in two patients with Tourette's syndrome and in none of the controls tested. An altered interaction between this miRNA and the SLITRK1 mRNA in the developing brain was suggested to contribute to this neuropsychiatric disorder. However this study has been treated with scepticism since a follow-up study indicated that the variant associated with Tourette Syndrome was overrepresented in certain subgroups such as Ashkenazi Jews, thereby complicating the interpretation of the results in a sample where cases and controls could happen to be not appropriately matched (Keen-Kim et al., 2006). After that, the putative importance of polymiRTS was strengthened by other studies involving SNPs affecting miRNA target sites with disease. Regarding those affecting the central nervous system two mutations were identified in the 3'UTR of the receptor expression enhancing protein 1 gene (REEP1), after previous association of this region with hereditary spastic paraplegia (Zuchner et al., 2006). These mutations were predicted to strengthen miR-140 mediated repression. Independently, in a similar approach, Beetz et al. identified one of these variants and discovered a third variant putatively affecting miR-691 regulation in two other hereditary spastic paraplegia families (Beetz et al., 2008). However, in these studies no functional experiments were performed. Jensen et al., aimed to study the role of miRNAs in human behaviours; as the deletion of serotonin receptor $1 \mathrm{~B}$ (HTR1B) has been shown to cause aggressive behaviour in mice, the authors analyzed the gene's 3'UTR. A common polymorphism in the serotonin receptor 1B affecting the target site for miR-96 was shown to be associated with aggressiveness in humans (Jensen et al., 2008). Finally, a polymorphism in fibroblast growth factor 20 (FGF20) conferring a risk to Parkinson's disease was shown to disrupt a miR-433 target site. Unlike other studies, the authors went further to provide human in vivo validation of this target site and a molecular mechanism by which differential miR-433 targeting leads to Parkinson's disease. According to their report, disruption of miR-433 target site leads to increased FGF20 translation, which in turn, increases alpha-synuclein expression and ultimately causes Parkinson's disease (Wang et al., 2008b).

\subsubsection{Trans-deregulation of miRNAs and anxiety disorder}

Under the same hypothesis, the possible implication in anxiety disorders of genetic variants affecting miRNA-mediated regulation of candidate genes has been already studied in the particular case of the neurotrophic tyrosine kinase 3 gene, NTRK3. Based on the recent discovery of miRNA-mediated regulation for different isoforms of this gene (Laneve et al., 2007; Guidi et al, 2010) NTRK3 was analyzed as a predisposition factor for anxiety disorders by re-sequencing the different 3'UTRs of two different isoforms of the gene (MuiñosGimeno et al., 2009). The study led to the identification of several variants in the 3'UTR of the truncated isoform of this gene (Table 1). Remarkably, one common SNP (rs28521337) 
was found to be associated with obsessive-compulsive disorder. Nevertheless, this association did not resist correction for multiple testing in the obsessive-compulsive disorder sample and was only statistically significant for the hoarding sub-clinical type of this disorder, suggesting a different pattern of genetic inheritance for this group of patients, which would be in agreement with recent reports that indicate that hoarding subphenotype may constitute a neurobiologically and etiologically distinct variant of obsessive-compulsive disorder (Miguel et al., 2005; Samuels et al., 2007), being highly heritable as a quantitative trait (Mathews et al., 2007). In the same study, other two rare variants in the 3'UTR of the truncated isoform of NTRK3 were identified, one of them is located in the target site and, specifically, in the sequence that binds to the seed region of miR-765 and the second variant in the target site for two different miRNAs, miR-509 and miR-128, the latter being a brainenriched miRNA involved in neuronal differentiation and synaptic processing. Interestingly, after mutagenesis and functional analyses of these two variants, both of them were shown to cause a significant alteration in the miRNA-mediated regulation of NTRK3 resulting in the recovery of gene expression when compared with the control sequence (Muiños-Gimeno et al., 2009). On the other hand, the contribution of rs28521337 to the susceptibility to obsessive-compulsive disorder remains unclear because, although the variant is located in the seed region of a validated target site for miR-485-3p, it did not significantly change the affinity and efficiency of this miRNA. Albeit it is possible that rs28521337 is only in linkage disequilibrium with the real cause of the disorder, the possibility that this SNP might be altering the expression of NTRK3 in a miRNA independent mechanism or that HeLa cells, the cell type used for the functional study, lack the additional cofactors required for the release of miRNA mediated repression of NTRK3 cannot be excluded. In this sense, it would be interesting to analyze the functional consequences of this SNP in a more biologically relevant context.

On the other hand, contribution to disease of the two rare allelic variants at the population level remains low, due to the fact that these variants were only identified in one male patient with panic disorder and agoraphobia, each. While it is widely accepted that rare allelic variants contribute little to heterozygosity, their putative role on disease cannot be ruled out as emphasized by the results on recent whole genome association studies, which have failed to identify major alleles for most of the disorders studied. These studies point out that susceptibility alleles are likely to be modest in effect size requiring large samples for detection (Sklar et al., 2008). Similarly, the rare allelic variant in the 3'UTR of SLITRK1 affecting the binding of miR-189 was only identified in two patients with Tourette syndrome and in none of the controls tested (Abelson et al., 2005). However, as previously mentioned, other groups (Keen-Kim et al. 2006) were unable to replicate the study and identified this rare allelic variant among cases and controls within the same families. In their opinion these results indicate that the variant does not segregate with the disease and that the results from Abelson et al. might be confounded by hidden population stratification (Keen-Kim et al., 2006). Confounding might originate on the fact that the screening for new causative allelic variants was carried out only in cases. Nevertheless, that the rare variant did not segregate completely with the disease may be explained, at least partly, by the difficulty, that the study of psychiatric disorders encompasses. In Tourette syndrome, as in anxiety disorders, diagnoses may not always be correctly assessed as most cases are mild and may remain undiagnosed. Moreover, genetic and environmental factors are likely to be involved in their aetiology and, consequently, among family members of an affected person, it is difficult to 
predict who else may be at risk of developing the condition, in other words, their inheritance patterns are unclear. This fact underlies a heterogenic basis of the disorder, in which cases substantially differ from one another, even though they are considered to suffer from the same disease. Thus, most probably, environmental factors, genetic epistasis and/or accumulation of rare variants might be on the back of the susceptibility to these disorders. Consistently, the case-control studies that we performed with the SNP panel covering miRNA regions in panic disorder resulted on moderate associations for several miRNA regions and, in addition, increase of risk in most of the cases was in general moderate as indicated by Odds Ratios and Confidence Intervals. These findings are therefore in line with the genetic heterogeneity theory proposed for anxiety disorders.

Other interesting methods used for the study of anxiety are based on a cross-species approach addressed to identify genes that regulate anxiety-like behaviour. Using this kind of approach, a SNP in the 3'UTR of the aminolevulinate dehydratase (ALAD) was found to be associated with social phobia. Even though this is not a true poly-miRTS study, this association is of particular interest since the authors comment on the possibility that this SNP generates an illegitimate target site for miR-211 and miR-204 -as predicted by a miRNA target prediction program- (Donner et al., 2008). In this regard, an important bottle-neck in the study of poly-miRTS is the identification of miRNA target sites itself. As part of the effort to understand interactions between miRNAs and their targets, computational algorithms have been developed based on observed rules for features, such as the degree of hybridization between the two RNA molecules. These in silico approaches provide important tools for miRNA target detection and, together with experimental validation, help to reveal miRNA target genes.

\section{Conclusions}

Anxiety disorders have long been believed to have abnormal neural regulatory mechanisms underlying symptom manifestation. We here propose that this deregulation is mediated, at least partially, by defective miRNA action, that consequently derives in dosage changes of proteins involved in central nervous system function. Mutations in miRNA target sites, such as those found in the NTRK3 gene, that might be affecting miRNA regulation, as well as anomalous dosage of miRNAs themselves, as observed for miR-18a, could be responsible for a disruption in the accurate equilibrium of complex brain functions, contributing to the development of anxiety disorders. In fact, miRNA expression differences between mice strains have been already showed to play a significant role in mice behaviour and have pinpointed to miR-34c and miR-323 as potential candidate genes for anxiety disorders. Moreover, the finding of at least four miRNAs (miR-22, miR-138-2, miR-148a and miR-488) associated with panic disorder that repress genes that have been previously involved in anxiety disorders, namely, NTRK3, RGS2, GABRA6, CCKBR, BDNF, HTR2C and MAOA, provides important new evidence that variation in genes coding for miRNAs may miscoordinate a number of risk genes and thereby contribute to the development of panic disorder. Taken together these data demonstrate the importance that alterations in the complex circuitry of gene regulation, in which miRNAs are involved, may have, not only in the fine functioning of the human central nervous system, but also in other physiological pathways linked to the development of stress-related disorders, further sustaining the hypothesis that miRNA-induced differential dosage may be participating in the aetiology of anxiety disorders. 


\section{Future perspectives}

Overall, the genetic complexity observed for anxiety disorders, where multiple alleles -rare or common- in protein coding genes or in regulatory elements might contribute independently to marginal increases of risk, together with the fact that these disorders are also influenced by environmental factors, evidences that traditional association analyses are probably underestimating the contribution of an analyzed locus to the studied disorder. In fact, methods based on linkage disequilibrium such as case-control analyses -using candidate genes or whole genome studies- have shown little success in identifying causative variants for anxiety disorders. Hence, the use of new high-throughput sequencing technologies and an increase of sample sizes would be of great help to dissect the underlying molecular causes of these complex disorders. In fact, the improvement and price reduction of these technologies are starting to make this type of analyses feasible nowadays. On the other hand, the recent and increasing evidence that supports an important role for regulatory regions in shaping phenotypes that, in last term, might be related to disease, makes the inclusion of these elements in future analyses of every single disorder of crucial importance. This is particularly true in the case of miRNAs; the rapid growth in the discovery of functional miRNA targets, as well as the involvement of new miRNA-related mechanisms in disease must be accompanied by an improvement in the tools needed to explore this new miRNA world. The latter should include the generation of proficient prediction algorithms and validation tools for the identification of miRNA target genes as well as generation of computational and experimental approaches to better understand how polymorphisms might be affecting pre-miRNA transcription, structure and mature miRNA expression and processing. In this sense, once potential causative allelic variants are identified, their contribution to disease remains always controversial and may only be assessed by means of functional experiments that demonstrate their possible involvement in the disorder. Accordingly, implementation of new functional approaches, as the ones presented along the chapter, are needed to identify candidate biological pathways involved in anxiety. We would finally like to encourage the current view that underlines the importance of converging data from genetics, analysis of cognitive function, study of animal models and neuroimaging in order to achieve a more integrative picture of complex human disorders in the near future.

\section{References}

Abelson, J. F., Kwan, K. Y., O'Roak, B. J., Baek, D. Y., Stillman, A. A., Morgan, T. M., Mathews, C. A., Pauls, D. L., Rasin, M. R., Gunel, M., Davis, N. R., Ercan-Sencicek, A. G., Guez, D. H., Spertus, J.A., Leckman, J. F., Dure, L. S. t., Kurlan, R., Singer, H. S.,Gilbert, D. L., Farhi, A., Louvi, A., Lifton, R. P., Sestan, N. \& State, M. W. (2005). Sequence variants in SLITRK1 are associated with Tourette's syndrome. Science 310, 317-20.

Adams, B. D., Furneaux, H. \& White, B. A. (2007). The micro-ribonucleic acid (miRNA) miR206 targets the human estrogen receptor-alpha (ERalpha) and represses ERalpha messenger RNA and protein expression in breast cancer cell lines. Molecular Endocrinology 21, 1132-47.

American Psychiatry Association. (2000). "Diagnostic and Statistical Manual of Mental Disorders, Fourth Edition, (DSM-IV), Text Revision." American Psychiatric Press, Washington, DC. 
Bartel, D. P. (2004). MicroRNAs: genomics, biogenesis, mechanism, and function. Cell 116, 281-97.

Beetz, C., Schule, R., Deconinck, T., Tran-Viet, K. N., Zhu, H., Kremer,B. P., Frints, S. G., van Zelst-Stams, W. A., Byrne, P., Otto, S.,Nygren, A. O., Baets, J., Smets, K., Ceulemans, B., Dan, B.,Nagan, N., Kassubek, J., Klimpe, S., Klopstock, T., Stolze, H.,Smeets, H. J., Schrander-Stumpel, C. T., Hutchinson, M., van de Warrenburg, B. P., Braastad, C., Deufel, T., Pericak-Vance, M., Schols, L., de Jonghe, P., \& Zuchner, S. (2008). REEP1 mutation spectrum and genotype/phenotype correlation in hereditary spastic paraplegia type 31 . Brain 131, 1078-86.

Beja-Pereira, A., Luikart, G., England, P. R., Bradley, D. G., Jann, O. C., Bertorelle, G., Chamberlain, A. T., Nunes, T. P., Metodiev, S., Ferrand, N., \& Erhardt, G. (2003). Gene-culture coevolution between cattle milk protein genes and human lactase genes. Nature Genetics 35, 311-3.

Bentwich, I. (2005). Prediction and validation of microRNAs and their targets. FEBS Letters 579, 5904-10.

Bespalova, I. N. \& Buxbaum, J. D. (2003). Disease susceptibility genes for autism. Annals of Medicine 35, 274-81.

Betel, D., Wilson, M., Gabow, A., Marks, D. S., Sander, C. (2008). The microRNA.org resource: targets and expression. Nucleic Acids Research 36, 149-53

Burmeister, M., McInnis, M. G. \& Zollner, S. (2008). Psychiatric genetics: progress amid controversy. Nature Review Genetics 9, 527-40.

Calin, G.A., Dumitru, C.D., Shimizu, M., Bichi, R., Zupo, S., Noch, E., Aldler, H., Rattan, S., Keating, M., Rai, K., Rassenti, L., Kipps, T., Negrini, M., Bullrich, F. \& Croce, C. M. (2002). Frequent deletions and down-regulation of micro- RNA genes miR15 and miR16 at 13q14 in chronic lymphocytic leukemia. Proc Natl Acad Sci U S A 99, 15524-9.

Calin, G. A., Sevignani, C., Dumitru, C. D., Hyslop, T., Noch, E., Yendamuri, S., Shimizu, M., Rattan, S., Bullrich, F., Negrini, M. \& Croce, C. M. (2004). Human microRNA genes are frequently located at fragile sites and genomic regions involved in cancers. Proc Natl Acad Sci U S A 101, 2999-3004.

Carleton, M., Cleary, M. A. \& Linsley, P. S. (2007). MicroRNAs and cell cycle regulation. Cell Cycle 6, 2127-32.

Chen, K. \& Rajewsky, N. (2006). Natural selection on human microRNA binding sites inferred from SNP data. Nature Genetics 38, 1452-6.

Cimmino, A., Calin, G. A., Fabbri, M., Iorio, M. V., Ferracin, M., Shimizu, M., Wojcik, S. E., Aqeilan, R. I., Zupo, S., Dono, M., Rassenti, L., Alder, H., Volinia, S., Liu, C. G., Kipps, T. J., Negrini, M. \& Croce, C. M. (2005). miR-15 and miR-16 induce apoptosis by targeting BCL2. Proc Natl Acad Sci U S A 102, 13944-9.

Costa, F. F.(2010). Non-coding RNAs: Meet thy masters. Bioessays 32, 599-608.

de Pontual, L., Népote, V., Attié-Bitach, T., Al Halabiah, H., Trang, H., Elghouzzi, V., Levacher, B., Benihoud, K., Augé, J., Faure, C., Laudier, B., Vekemans, M., Munnich, A., Perricaudet, M., Guillemot, F., Gaultier, C., Lyonnet, S., Simonneau, M, Amiel, J. (2003). Noradrenergic neuronal development is impaired by mutation of the proneural HASH-1 gene in congenital central hypoventilation syndrome (Ondine's curse). Hum Mol Genet 2, 3173-80 
Donner, J., Pirkola, S., Silander, K., Kananen, L., Terwilliger, J. D., Lonnqvist, J., Peltonen, L. \& Hovatta, I. (2008). An association analysis of murine anxiety genes in humans implicates novel candidate genes for anxiety disorders. Biological Psychiatry 64, 672-80.

Eletto, D., Russo, G., Passiatore, G., Del Valle, L., Giordano, A., Khalili, K., Gualco, E. \& Peruzzi, F. (2008). Inhibition of SNAP25 expression by HIV-1 Tat involves the activity of mir-128a. J Cell Physiol 216, 764-70.

Erson, A. E. \& Petty, E. M. (2008). MicroRNAs in development and disease. Clinical Genetics 74, 296-306.

Filipowicz, W., Bhattacharyya, S. N. \& Sonenberg, N. (2008). Mechanisms of posttranscriptional regulation by microRNAs: are the answers in sight? Nature Review Genetics 9, 102-14.

Fiore, R. \& Schratt, G. (2007). MicroRNAs in vertebrate synapse development. Scientific World Journal 7, 167-77.

Gelder MG, L.-I. J., Andreasen (2001). "New Oxford Textbook of Psychiatry." Oxford University Press, Oxford.

Goldstein, R. B., Wickramaratne, P. J., Horwath, E. \& Weissman, M. M. (1997). Familial aggregation and phenomenology of 'early'-onset (at or before age 20 years) panic disorder. Archives of General Psychiatry 54, 271-8.

Gong, H., Liu, C. M., Liu, D. P. \& Liang, C. C. (2005). The role of small RNAs in human diseases: potential troublemaker and therapeutic tools. Medical Research Reviews 25, 361-81.

Gorman, J. M., Kent, J. M., Sullivan, G. M. \& Coplan, J. D. (2000). Neuroanatomical hypothesis of panic disorder, revised. The American Journal of Psychiatry 157, 493505.

Gratacos, M., Sahun, I., Gallego, X., Amador-Arjona, A., Estivill, X. \& Dierssen, M. (2007). Candidate genes for panic disorder: insight from human and mouse genetic studies.Genes Brain and Behavior 6 Suppl 1, 2-23.

Grisham, J. R., Anderson, T. M. \& Sachdev, P. S. (2008). Genetic and environmental influences on obsessive-compulsive disorder. European Archives of Psychiatry and Clinical Neurosciences 258, 107-16.

Guidi, M., Muiños-Gimeno, M., Kagerbauer, B., Martí, E., Estivill, X., Espinosa-Parrilla, Y. (2010). Overexpression of miR-128 specifically inhibits the truncated isoform of NTRK3 and upregulates BCL2 in SH-SY5Y neuroblastoma cells. BMC Molecular Biology 11, 95.

Gupta, A. R. \& State, M. W. (2007). Recent advances in the genetics of autism. Biol Psychiatry 61, 429-37.

Hansen, T., Olsen, L., Lindow, M., Jakobsen, K. D., Ullum, H., Jonsson, E., Andreassen, O. A., Djurovic, S., Melle, I., Agartz, I., Hall, H., Timm, S., Wang, A. G. \& Werge, T. (2007). Brain expressed microRNAs implicated in schizophrenia etiology.PLoS ONE $2, \mathrm{e} 873$.

He, L., He, X., Lim, L. P., de Stanchina, E., Xuan, Z., Liang, Y., Xue, W., Zender, L., Magnus, J., Ridzon, D., Jackson, A. L., Linsley, P. S., Chen, C., Lowe, S. W., Cleary, M. A. \& Hannon, G. J. (2007). A microRNA component of the p53 tumour suppressor network. Nature 447, 1130-4.

Hebert, S. S., Horre, K., Nicolai, L., Papadopoulou, A. S., Mandemakers, W., Silahtaroglu, A. N., Kauppinen, S., Delacourte, A. \& De Strooper, B. (2008). Loss of microRNA 
cluster miR-29a/b-1 in sporadic Alzheimer's disease correlates with increased BACE1/beta-secretase expression. Proc Natl Acad Sci U S A 105, 6415-20.

Hettema, J. M., An, S. S., van den Oord, E. J., Neale, M. C., Kendler, K. S. \& Chen, X. (2008). Association study between the serotonin 1A receptor (HTR1A) gene and neuroticism, major depression, and anxiety disorders. American Journal of Medical Genetics Part B Neuropsychiatric Genetics 147B, 661-6.

Hillebrand, J., Barbee, S. A. \& Ramaswami, M. (2007). P-body components, microRNA regulation, and synaptic plasticity. Scientifi World Journal 7, 178-90.

Hollox, E. (2005). Evolutionary genetics: genetics of lactase persistence--fresh lessons in the history of milk drinking. European Journal of Human Genetics 13, 267-9.

Hudder, A. \& Novak, R. F. (2008). miRNAs: effectors of environmental influences on gene expression and disease. Toxicology Sciences 103, 228-40.

Jazdzewski, K., Liyanarachchi, S., Swierniak, M., Pachucki, J., Ringel, M. D., Jarzab, B. \& de la Chapelle, A. (2009). Polymorphic mature microRNAs from passenger strand of pre-miR-146a contribute to thyroid cancer. Proc Natl Acad Sci U S A 106, 1502-5.

Jazdzewski, K., Murray, E. L., Franssila, K., Jarzab, B., Schoenberg, D. R. \& de la Chapelle, A. (2008). Common SNP in pre-miR-146a decreases mature miR expression and predisposes to papillary thyroid carcinoma. Proc Natl Acad Sci U S A 105, 7269-74.

Jensen, K. P., Covault, J., Conner, T. S., Tennen, H., Kranzler, H. R. \& Furneaux, H. M. (2008). A common polymorphism in serotonin receptor 1B mRNA moderates regulation by miR-96 and associates with aggressive human behaviors. Molecular Psychiatry.

Jin, P., Zarnescu, D. C., Ceman, S., Nakamoto, M., Mowrey, J., Jongens, T. A., Nelson, D. L., Moses, K. \& Warren, S. T. (2004). Biochemical and genetic interaction between the fragile $X$ mental retardation protein and the microRNA pathway. Nature Neurosciences 7, 113-7.

Kawahara, Y., Zinshteyn, B., Sethupathy, P., Iizasa, H., Hatzigeorgiou, A. G. \& Nishikura, K. (2007). Redirection of silencing targets by adenosine-to-inosine editing of miRNAs. Science 315, 1137-40.

Kawaji, H. \& Hayashizaki, Y. (2008). Exploration of small RNAs. PLoS Genetics 4, e22.

Keen-Kim, D., Mathews, C. A., Reus, V. I., Lowe, T. L., Herrera, L. D., Budman, C. L., GrossTsur, V., Pulver, A. E., Bruun, R. D., Erenberg, G., Naarden, A., Sabatti, C. \& Freimer, N. B. (2006). Overrepresentation of rare variants in a specific ethnic group may confuse interpretation of association analyses. Human Molecular Genetics 15, 3324-8.

Kessler, R. C., Berglund, P., Demler, O., Jin, R., Merikangas, K. R. \& Walters, E. E. (2005). Lifetime prevalence and age-of-onset distributions of DSM-IV disorders in the National Comorbidity Survey Replication. Archives of General Psychiatry 62, 593-602.

Kessler, R. C., Amminger G.P., Aguilar-Gaxiola S., Alonso J., Lee S. \& Ustün T.B. (2007). Age of onset of mental disorders: a review of recent literature. Current Opinion in Psychiatry 20, 359-64.

Kessler, R. C., Aguilar-Gaxiola S., Alonso J., Chatterji S., Lee S., Ormel J., Ustün T.B. \& Wang P.S. (2009). The global burden of mental disorders: an update from the WHO World Mental Health (WMH) surveys. Epidemiologia Psichiatria Sociale 18, 23-33.

Kieseppa, T., Partonen, T., Haukka, J., Kaprio, J. \& Lonnqvist, J. (2004). High concordance of bipolar I disorder in a nationwide sample of twins. Am J Psychiatry 161, 1814-21. 
Kim, J., Inoue, K., Ishii, J., Vanti, W. B., Voronov, S. V., Murchison, E., Hannon, G. \& Abeliovich, A. (2007). A MicroRNA feedback circuit in midbrain dopamine neurons. Science 317, 1220-4.

Knight, J. C. (2005). Regulatory polymorphisms underlying complex disease traits. J Mol Med 83, 97-109.

Koenen, K. C., Amstadter, A. B., Ruggiero, K. J., Acierno, R., Galea, S., Kilpatrick, D. G. \& Gelernter, J. (2009). RGS2 and generalized anxiety disorder in an epidemiologic sample of hurricane-exposed adults. Depression and Anxiety Journal 26, 309-15.

Kosik, K. S. (2006). The neuronal microRNA system. Nature Review of Neurosciences 7, 911-20.

Krol, J., Loedige, I., Filipowicz, W. (2010). The widespread regulation of microRNA biogenesis, function and decay. Nature Review Genetics 11, 597-610.

Lagos-Quintana, M., Rauhut, R., Lendeckel, W. \& Tuschl, T. (2001). Identification of novel genes coding for small expressed RNAs. Science 294, 853-8.

Landi, D., Gemignani, F., Naccarati, A., Pardini, B., Vodicka, P.,Vodickova, L., Novotny, J., Forsti, A., Hemminki, K., Canzian, F. \& Landi, S. (2008). Polymorphisms within micro-RNA-binding sites and risk of sporadic colorectal cancer. Carcinogenesis 29, 57984.

Landthaler, M., Yalcin, A. \& Tuschl, T. (2004). The human DiGeorge syndrome critical region gene 8 and Its $\mathrm{D}$. melanogaster homolog are required for miRNA biogenesis. Current Biology 14, 2162-7.

Laneve, P., Di Marcotullio, L., Gioia, U., Fiori, M. E., Ferretti, E., Gulino, A., Bozzoni, I. \& Caffarelli, E. (2007). The interplay between microRNAs and the neurotrophin receptor tropomyosin-related kinase $C$ controls proliferation of human neuroblastoma cells. Proc Natl Acad Sci U S A 104, 7957-62.

Lau, N. C., Lim, L. P., Weinstein, E. G. \& Bartel, D. P. (2001). An abundant class of tiny RNAs with probable regulatory roles in Caenorhabditis elegans. Science 294, 858-62.

Lee, R. C. \& Ambros, V. (2001). An extensive class of small RNAs in Caenorhabditis elegans. Science 294, 862-4.

Lee, R. C., Feinbaum, R. L. \& Ambros, V. (1993). The C. elegans heterochronic gene lin-4 encodes small RNAs with antisense complementarity to lin-14. Cell 75, 843-54.

Lewis, B. P., Shih, I. H., Jones-Rhoades, M. W., Bartel, D. P. \& Burge, C. B. (2003). Prediction of mammalian microRNA targets. Cell 115, 787-98.

Li, X. F., Stutzmann, G. E. \& LeDoux, J. E. (1996). Convergent but temporally separated inputs to lateral amygdala neurons from the auditory thalamus and auditory cortex use different postsynaptic receptors: in vivo intracellular and extracellular recordings in fear conditioning pathways. Learning and Memory 3, 229-42.

Locatelli, I., Lichtenstein, P. \& Yashin, A. I. (2004). The heritability of breast cancer: a Bayesian correlated frailty model applied to Swedish twins data. Twin Research 7, 182-91.

Lukiw, W. J. (2007). Micro-RNA speciation in fetal, adult and Alzheimer's disease hippocampus.Neuroreport 18, 297-300.

Lupien, S. J., McEwen, B. S., Gunnar, M. R., Heim, C. (2009). Effects of stress throughout the lifespan on the brain, behaviour and cognition. Nat Rev Neurosci 10, 434-45

Maron, E., Hettema, J. M., Shlik, J. (2010). Advances in molecular genetics of panic disorder. Molecular Psychiatry. 15, 681-701. 
Mataix-Cols, D. (2006). Deconstructing obsessive-compulsive disorder: a multidimensional perspective. Current Opion in Psychiatry 19, 84-9.

Mataix-Cols, D., Rosario-Campos, M. C. \& Leckman, J. F. (2005). A multidimensional model of obsessive-compulsive disorder. Am J Psychiatry 162, 228-38.

Mathews, C. A., Nievergelt, C. M., Azzam, A., Garrido, H., Chavira, D. A., Wessel, J., Bagnarello, M., Reus, V. I. \& Schork, N. J. (2007). Heritability and clinical features of multigenerational families with obsessive-compulsive disorder and hoarding. American Journal of Medical Genetics Part B Neuropsychiatric Genetics 144, 174-82.

Mattick, J. S. (2009).The genetic signatures of noncoding RNAs. PLoS Genetics 5, e100045

McLaughlin, K. A. \& Hatzenbuehler, M. L. (2009). Stressful life events, anxiety sensitivity, and internalizing symptoms in adolescents. Journal of Abnormal Psychology 118, 659-69.

Miguel, E. C., Leckman, J. F., Rauch, S., do Rosario-Campos, M. C., Hounie, A. G., Mercadante, M. T., Chacon, P. \& Pauls, D. L. (2005). Obsessive-compulsive disorder phenotypes: implications for genetic studies. Molecular Psychiatry 10, 258-75.

Mishra, P. J., Humeniuk, R., Mishra, P. J., Longo-Sorbello, G. S., Banerjee, D. \& Bertino, J. R. (2007). A miR-24 microRNA binding-site polymorphism in dihydrofolate reductase gene leads to methotrexate resistance. Proc Natl Acad Sci U S A 104, 13513-8.

Muiños-Gimeno, M., Guidi, M., Kagerbauer, B., Martín-Santos, R., Navinés, R., Alonso, P., Menchón, J. M., Gratacòs, M., Estivill, X. \& Espinosa-Parrilla, Y. (2009). Allele variants in functional MicroRNA target sites of the neurotrophin-3 receptor gene (NTRK3) as susceptibility factors for anxiety disorders. Human Mutation 30:1062-71.

Muiños-Gimeno M, Montfort M, Bayés M, Estivill X, Espinosa-Parrilla Y.(2010). Design and evaluation of a panel of single-nucleotide polymorphisms in microRNA genomic regions for association studies in human disease. European Journal of Human Genetics 18:218-26

Muiños-Gimeno, M., Espinosa-Parrilla, Y., Guidi, M., Kagerbauer, B., Sipilä, T., Maron, E., Pettai, K., Kananen, L., Navinés, R., Martín-Santos, R., Gratacòs, M., Metspalu, A., Hovatta, I. \& Estivill, X. (2011). Human microRNAs miR-22, miR-138-2, miR-148a, and miR-488 are associated with panic disorder and regulate several anxiety candidate genes and related pathways. Biological Psychiatry 69:526-33

Noyes, R., Jr., Crowe, R. R., Harris, E. L., Hamra, B. J., McChesney, C. M. \& Chaudhry, D. R. (1986). Relationship between panic disorder and agoraphobia. Archives of General Psychiatry 43, 227-32.

Pattyn, A., Simplicio, N., van Doorninck, J.H ., Goridis, C., Guillemot, F., Brunet, J. F. (2004). Ascl1/Mash1 is required for the development of central serotonergic neurons. Nature Neurosciences 7, $589-595$

Pauley, K. M. \& Chan, E. K. (2008). MicroRNAs and their emerging roles in immunology. Annals of the New York Academy of Sciences 1143, 226-39.

Penagarikano, O., Mulle, J. G. \& Warren, S. T. (2007). The pathophysiology of fragile $x$ syndrome. Annual Review of Genomics and Human Genetics 8, 109-29.

Perkins, D. O., Jeffries, C. D., Jarskog, L. F., Thomson, J. M., Woods, K., Newman, M. A., Parker, J. S., Jin, J. \& Hammond, S. M. (2007). microRNA expression in the prefrontal cortex of individuals with schizophrenia and schizoaffective disorder. Genome Biology 8, R27.

Parsons, M,J., Grimm, C,H, Paya-Cano, J,L., Sugden, K., Nietfeld, W., Lehrach, H. \& Schalkwyk, L.C. (2008). Using hippocampal microRNA expression differences 
between mouse inbred strains to characterise miRNA function. Mammalian Genome 19, 552-60.

Perna, G., Caldirola, D., Arancio, C. \& Bellodi, L. (1997). Panic attacks: a twin study. Psychiatry Research 66, 69-71.

Plomin, R., Owen, M. J. \& McGuffin, P. (1994). The genetic basis of complex human behaviors. Science 264, 1733-9.

Poy, M. N., Eliasson, L., Krutzfeldt, J., Kuwajima, S., Ma, X., Macdonald, P. E., Pfeffer, S., Tuschl, T., Rajewsky, N., Rorsman, P. \& Stoffel, M. (2004). A pancreatic islet-specific microRNA regulates insulin secretion. Nature 432, 226-30.

Quach, H., Barreiro, L. B., Laval, G., Zidane, N., Patin, E., Kidd, K. K., Kidd, J. R., Bouchier, C., Veuille, M., Antoniewski, C. \& Quintana-Murci, L. (2009). Signatures of purifying and local positive selection in human miRNAs. American Journal of Human Genetics 84, 31627.

Regier, D. A., Narrow, W. E. \& Rae, D. S. (1990). The epidemiology of anxiety disorders: the Epidemiologic Catchment Area (ECA) experience. Journal of Psychiatric Research 24 Suppl 2, 3-14.

Rockman, M. V. \& Wray, G. A. (2002). Abundant raw material for cis-regulatory evolution in humans. Molecular Biology and Evolution 19, 1991-2004.

Samuels, J. F., Bienvenu, O. J., 3rd, Pinto, A., Fyer, A. J., McCracken, J. T., Rauch, S. L., Murphy, D. L., Grados, M. A., Greenberg, B. D., Knowles, J. A., Piacentini, J., Cannistraro, P. A., Cullen, B., Riddle, M. A., Rasmussen, S. A., Pauls, D. L., Willour, V. L., Shugart, Y. Y., Liang, K. Y., Hoehn-Saric, R. \& Nestadt, G. (2007). Hoarding in obsessive-compulsive disorder: results from the OCD Collaborative Genetics Study. Behaviour Research and Therapy 45, 673-86.

Sansone, R. A., Sansone, L. A. \& Righter, E. L. (1998). Panic disorder: the ultimate anxiety. Journal of Womens Health 7, 983-9.

Saunders, M. A., Liang, H. \& Li, W. H. (2007). Human polymorphism at microRNAs and microRNA target sites. Proc Natl Acad Sci U S A 104, 3300-5.

Schildkraut, J. M., Risch, N. \& Thompson, W. D. (1989). Evaluating genetic association among ovarian, breast, and endometrial cancer: evidence for a breast/ovarian cancer relationship. American Journal of Human Genetics45, 521-9.

Schratt, G. M., Tuebing, F., Nigh, E. A., Kane, C. G., Sabatini, M. E., Kiebler, M. \& Greenberg, M. E. (2006). A brain-specific microRNA regulates dendritic spine development. Nature 439, 283-9.

Sethupathy, P., Megraw, M. \& Hatzigeorgiou, A. G. (2006). A guide through present computational approaches for the identification of mammalian microRNA targets. Nature Methods 3, 881-6.

Sethupathy, P., Borel, C., Gagnebin, M., Grant, G. R., Deutsch, S., Elton, T. S., Hatzigeorgiou, A. G. \& Antonarakis, S. E. (2007). Human microRNA-155 on chromosome 21 differentially interacts with its polymorphic target in the AGTR1 3' untranslated region: a mechanism for functional single-nucleotide polymorphisms related to phenotypes. American Journal of Human Genetics 81, 405-13.

Siegel, G., Obernosterer, G., Fiore, R., Oehmen, M., Bicker, S., Christensen, M., Khudayberdiev, S., Leuschner, P. F., Busch, C. J., Kane, C., Hubel, K., Dekker, F., Hedberg, C., Rengarajan, B., Drepper, C., Waldmann, H., Kauppinen, S., Greenberg, M. E., Draguhn, A., Rehmsmeier, M., Martinez, J. \& Schratt, G. M. 
(2009). A functional screen implicates microRNA-138-dependent regulation of the depalmitoylation enzyme APT1 in dendritic spine morphogenesis.Nature Cell Biology 11, 705-16.

Sklar, P., Smoller, J. W., Fan, J., Ferreira, M. A., Perlis, R. H., Chambert, K., Nimgaonkar, V. L., McQueen, M. B., Faraone, S. V., Kirby, A., de Bakker, P. I., Ogdie, M. N., Thase, M. E., Sachs, G. S., Todd-Brown, K., Gabriel, S. B., Sougnez, C., Gates, C., Blumenstiel, B., Defelice, M., Ardlie, K. G., Franklin, J., Muir, W. J., McGhee, K. A., MacIntyre, D. J., McLean, A., VanBeck, M., McQuillin, A., Bass, N. J., Robinson, M., Lawrence, J., Anjorin, A., Curtis, D., Scolnick, E. M., Daly, M. J., Blackwood, D. H., Gurling, H. M. \& Purcell, S. M. (2008). Whole-genome association study of bipolar disorder. Molecular Psychiatry 13, 558-69.

Smoller, J. W. \& Tsuang, M. T. (1998). Panic and phobic anxiety: defining phenotypes for genetic studies. American Journal of Psychiatry 155, 1152- 62.

Stark, A., Brennecke, J., Bushati, N., Russell, R. B. \& Cohen, S. M. (2005). Animal MicroRNAs confer robustness to gene expression and have a significant impact on 3'UTR evolution. Cell 123, 1133-46.

Stein, D. J. (2002). Obsessive-compulsive disorder. Lancet 360, 397-405.

Sullivan, G. M., Coplan, J. D., Kent, J. M. \& Gorman, J. M. (1999). The noradrenergic system in pathological anxiety: a focus on panic with relevance to generalized anxiety and phobias. Biological Psychiatry 46, 1205-18.

Sullivan, P. F., Kendler, K. S. \& Neale, M. C. (2003). Schizophrenia as a complex trait: evidence from a meta-analysis of twin studies. Archives of General Psychiatry 60, 1187-92.

Sun, B. K. \& Tsao, H. (2008). Small RNAs in development and disease. Journal of the American Academy of Dermatology 59, 725-37; quiz 738-40.

Swaab, D. F., Bao, A. M. \& Lucassen, P. J. (2005). The stress system in the human brain in depression and neurodegeneration. Ageing Research Review 4, 141-94.

Taganov, K. D., Boldin, M. P., Chang, K. J. \& Baltimore, D. (2006). NF-kappaB-dependent induction of microRNA miR-146, an inhibitor targeted to signaling proteins of innate immune responses. Proc Natl Acad Sci U S A 103, 12481-6.

Tan, Z., Randall, G., Fan, J., Camoretti-Mercado, B., Brockman-Schneider, R., Pan, L., Solway, J., Gern, J. E., Lemanske, R. F., Nicolae, D. \& Ober, C. (2007). Allele-specific targeting of microRNAs to HLA-G and risk of asthma. American Journal of Human Genetics 81, 829-34.

Taupenot, L., Harper, K. L., O'Connor, D. T. (2003). The chromogranin-secretogranin family. The New England Journal of Medicine 348, 1134 -49.

Torgersen, S. (1983). Genetic factors in anxiety disorders. Archives of General Psychiatry 40, 1085-9.

Tsui, C. C., Copeland, N. G., Gilbert, D. J., Jenkins, N. A., Barnes, C., Worley, P. F. (1996). Narp, a novel member of the pentraxin family, promotes neurite outgrowth and is dynamically regulated by neuronal activity. Journal of Neurosciences 16, 2463-78.

Uchida S, Nishida A, Hara K, Kamemoto T, Suetsugi M, Fujimoto M, Watanuki T, Wakabayashi Y, Otsuki K, McEwen BS, Watanabe Y. (2008). Characterization of the vulnerability to repeated stress in Fischer 344 rats: possible involvement of microRNA-mediated down-regulation of the glucocorticoid receptor. European Journal of Neurosciences 27, 2250-61 
van den Heuvel, O. A., van de Wetering, B. J., Veltman, D. J. \& Pauls, D. L. (2000). Genetic studies of panic disorder: a review. Journal of Clinical Psychiatry 61, 756-66.

Wang, W. X., Rajeev, B. W., Stromberg, A. J., Ren, N., Tang, G., Huang, Q., Rigoutsos, I. \& Nelson, P. T. (2008a). The expression of microRNA miR-107 decreases early in Alzheimer's disease and may accelerate disease progression through regulation of beta-site amyloid precursor protein-cleaving enzyme 1.Journal of Neurosciences 28, 1213-23.

Wang G., van der Walt J.M., Mayhew G., Li Y.J., Züchner S., Scott W.K., Martin E.R. \&Vance J.M. (2008b). Variation in the miRNA-433 binding site of FGF20 confers risk for Parkinson disease by overexpression of alpha-synuclein. American Journal of Human Genetics 82, 283-9.

Weiller, E., Bisserbe, J. C., Maier, W. \& Lecrubier, Y. (1998). Prevalence and recognition of anxiety syndromes in five European primary care settings. A report from the WHO study on Psychological Problems in General Health Care. Brithish Journal of Psychiatry Suppl 34, 18-23.

Weissman, M. M., Bland, R. C., Canino, G. J., Faravelli, C., Greenwald, S., Hwu, H. G., Joyce, P. R., Karam, E. G., Lee, C. K., Lellouch, J., Lepine, J. P., Newman, S. C., OakleyBrowne, M. A., Rubio-Stipec, M., Wells, J. E., Wickramaratne, P. J., Wittchen, H. U. \& Yeh, E. K. (1997). The cross-national epidemiology of panic disorder. Archives of General Psychiatry 54, 305-9.

Wu, M., Jolicoeur, N., Li, Z., Zhang, L., Fortin, Y., L'Abbe, D., Yu, Z., Shen , S. Z., (2008). Genetic variations of microRNAs in human cancer and their effects on the expression of miRNAs. Carcinogenesis 29, 1710-6

Yalcin, B., Willis-Owen, S. A., Fullerton, J., Meesaq, A., Deacon, R. M., Rawlins, J. N., Copley, R. R., Morris, A. P., Flint, J. \& Mott, R. (2004). Genetic dissection of a behavioral quantitative trait locus shows that Rgs2 modulates anxiety in mice. Nature Genetics 36, 1197-202.

Zuchner, S., Wang, G., Tran-Viet, K. N., Nance, M. A., Gaskell, P. C., Vance, J. M., AshleyKoch, A. E. \& Pericak-Vance, M. A. (2006). Mutations in the novel mitochondrial protein REEP1 cause hereditary spastic paraplegia type 31. American Journal of Human Genetics 79, 365-9. 


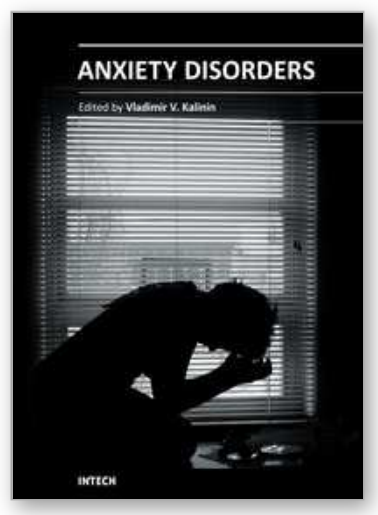

\author{
Anxiety Disorders \\ Edited by Prof. Vladimir Kalinin
}

ISBN 978-953-307-592-1

Hard cover, 324 pages

Publisher InTech

Published online 01, August, 2011

Published in print edition August, 2011

During the last 2-3 decades drastic research progress in anxiety issues has been achieved. It concerns mostly the study of different subtypes of anxiety and their treatment. Nevertheless, the data on anxiety pathogenesis is less elaborated, although here a multidimensional approach exists. It includes neurochemistry, pathophysiology, endocrinology and psychopharmacology. Again, we are able to recognize the multifarious sense of anxiety, and the present collective monograph composed of 16 separate chapters depicting the different aspects of anxiety. Moreover, a great part of book includes chapters on neurochemistry, physiology and pharmacology of anxiety. The novel data on psychopathology and clinical signs of anxiety and its relationship with other psychopathological phenomena is also presented. The current monograph may represent an interest and be of practical use not only for clinicians but for a broad range of specialists, including biochemists, physiologists, pharmacologists and specialists in veterinary.

\title{
How to reference
}

In order to correctly reference this scholarly work, feel free to copy and paste the following:

Yolanda Espinosa-Parrilla and Margarita Muiños-Gimeno (2011). MicroRNA-Mediated Regulation and the Genetic Susceptibility to Anxiety Disorders, Anxiety Disorders, Prof. Vladimir Kalinin (Ed.), ISBN: 978-953-307592-1, InTech, Available from: http://www.intechopen.com/books/anxiety-disorders/microrna-mediatedregulation-and-the-genetic-susceptibility-to-anxiety-disorders 1

\section{INTECH}

open science | open minds

\section{InTech Europe}

University Campus STeP Ri

Slavka Krautzeka 83/A

51000 Rijeka, Croatia

Phone: +385 (51) 770447

Fax: +385 (51) 686166

www.intechopen.com

\section{InTech China}

Unit 405, Office Block, Hotel Equatorial Shanghai

No.65, Yan An Road (West), Shanghai, 200040, China

中国上海市延安西路65号上海国际贵都大饭店办公楼 405 单元

Phone: +86-21-62489820

Fax: $+86-21-62489821$ 
(C) 2011 The Author(s). Licensee IntechOpen. This chapter is distributed under the terms of the Creative Commons Attribution-NonCommercialShareAlike-3.0 License, which permits use, distribution and reproduction for non-commercial purposes, provided the original is properly cited and derivative works building on this content are distributed under the same license. 